\title{
Improving Communication Ability of a Child with Selective Mutism Through "Kita Semua Sahabat" Training
}

\author{
Puspita Adhi Kusuma Wijayanti ${ }^{1}$, Murtini $^{2}$ \\ ${ }^{1}$ Faculty of Pscyhology, Universitas Padjadjaran \\ ${ }^{2}$ Faculty of Psychology, Universitas Gadjah Mada
}

\section{Submitted 10 March 2020 Accepted 17 September 2021 Published 30 October 2021}

\begin{abstract}
Selective Mutism (SM) is characterized by failure to speak at some period of time in specific social situations (e.g., at school), but can talk in other familiar situations (home). This study aimed to determine the effectiveness of 'Kita Semua Sahabat' in improving communication skills in children with SM. The subject was a 5 year-old boy who had been diagnosed based on DSM-V. The research design was a single case experimental design. Interventions were performed using the technique of stimulus fading and contingency management which were packed through the training of 'Kita Semua Sahabat'. The result showed that there was a significant increase, and communication with stimulus (prompts) had a greater increase than communication without stimulus (child's initiation). The research showed that Training 'Kita Semua Sahabat' is effective to increase communication among children with $\mathrm{SM}$, and more frequent verbal communication happens if more stimuli were given to the child.
\end{abstract}

Keywords: communication; initiation; prompts; selective mutism

Early childhood is the development period that happens from the end of the baby phase till the age of around 5 years or 6 years, sometimes this period is called preschool age (Santrock, 2018). Social interaction, mainly contact with parents, siblings, teachers, and friends of the same age become the contributor which is important to the social-cognitive development in this age. This is because children need to know someone else, someone should be able to accept their perspective and understand their thinking, motives, feeling, and intention (Shaffer, 2009). Nevertheless, some children find it difficult to make social interactions with the environment outside the family. They keep silent and are unable to say a word with friends or their teachers at school, but they are able to speak at home. Their silence does not only happen in the school environment but also other social environments. A child with this characteristic is also called Selective Mutism or SM (Ponzurick, 2012).

Selective Mutism (SM) is a term for a child who keeps failing to speak in the specific social situation when he/she is expected to speak (for instance at school), but consistently speaks in other social situations (for instance at home) (American Psychiatric Association [APA], 2013). Classrooms are often become the place for students who lose their speech, and this case needs to be concerned and has the most problem of academic and social expectation at the school (Shriver et al., 2011). The prevalence of SM ranges 
from $0.03 \%$ to $1 \%$, depending on the sampling setting (e.g. clinic vs school vs general population) and the ages of the individuals in the sample (APA, 2013). The prevalence in a school setting is higher because the classroom becomes a place where anxiety arises and is more frequent among girls than boys (Muris \& Ollendick, 2015; Shriver et al., 2011).

Several studies have reported the effects of SM, e.g. may show less social competence in both nonverbal and verbal social situations because of their withdrawal from social interaction (Carbone et al., 2010), and may have difficulty making friends (Diliberto \& Kearney, 2016). Not only in the social setting, the effect of SM is also reported in the academic setting. A study found that children with SM got a lower score in the cognitive nonverbal measurement (Manassis et al., 2007), and lower academic performance (Nowakowski et al., 2009). A recent study also found that teachers show a greater difficulty to establish a relationship based on affective closeness with a child affected by SM, compared to that with unaffected children (Longobardi et al., 2019).

Behaviorist theory viewed SM as the negative reinforcement from behavior learning which is reinforced negatively. The child refuses to speak not to attract teachers' attention but as their comfort to the class behavior expectation (Krysanski, 2003). SM is viewed from a behavioral concept as habituation of anxiety that is maintained. The response from increasing anxiety is preventing speaking, hence it can reduce the anxiety, and then the people surrounding him will stop asking them to speak. The reinforcement will make the child think that their silent behavior succeeds in decreasing anxiety. This situation continues and is well maintained (Bergman, 2013).

\section{Figure 1.}

Habituation Pattern of Selective Mutism Child (Bergman, 2013)

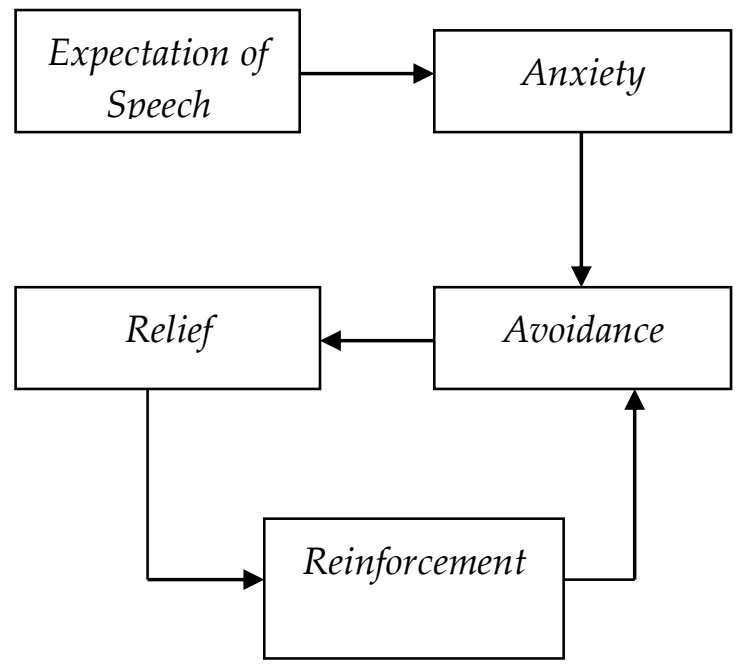

Intervention with SM children aims to reduce their anxiety and increase selfconfidence in a social situation. Forcing the child to speak will not be effective because the 
ability to speak will appear along when their anxiety decreases and self-confidence increases (Shipon Blum, 2003). The behavioral modification uses treatment; such as: shaping, stimulus fading, contingency management, and positive reinforcement; intended to reduce their anxiety, increase self-confidence and promote speaking (Fernandez \& Sugay, 2016). Some researchers reported the effectiveness of stimulus fading and contingency management to improve communication of children with SM (Beare et al., 2008; Hartono, 2010; Moldan, 2005; Shriver et al., 2011; Vecchio, 2009).

Stimulus fading refers to gradually increased exposure to a fear-evoking stimulus (Shabani \& Fisher, 2006), and contingency management refers to giving a reward or positive reinforcement for every evidence of positive behavioral change (Petry, 2011). In SM children, an anxious situation is presented gradually into a relaxed situation such as playing. The aim is to reduce anxiety. As the child's anxiety level decreases, he will begin to participate and communicate then receive a reward as positive reinforcement. When he succeeds in communicating in one situation, then the anxiety level will be upgraded into a wider context and more people inside. These habituation patterns will slowly reduce their anxiety, increase confidence and improve communication (Bergman, 2013; Shipon Blum, 2003).

Therefore, in this study, the techniques of stimulus fading and contingency management were packaged in a training namely Training "Kita Semua Sahabat". The training consists of 10 sessions and involved a total of 7 classmates and a class teacher. The novelty of this research was the measurement of intervention results which were divided into 2 communication, namely communication with the stimulus (prompt communication, for example when children are asked or appointed to speak), and communication without stimulus (initiative communication, for example, stretching fingers to ask questions). Both prompt communication and initiative communication were observed in verbal and nonverbal communication. The division of communication was based on that communication with prompt and initiative are different in nature. Starting a conversation (initiative communication) is something difficult for SM children, and it requires a long process (Shriver et al., 2011).

The hypotheses of the study were (1) Training "Kita Semua Sahabat" can improve verbal communication to SM Child, and (2) The increase of verbal prompt communication is bigger than verbal initiative communication.

\section{Method}

The study was a single case experimental design research with the A-B-A design. Phase A was a baseline phase that contained a number of observations of the behavior which had been the target in the natural situation (before the intervention). Phase B was the phase in which the intervention or the treatment was given, by considering the change of the phase which contains a number of the observation series from the behavior which has been the 
target in the natural situation (before the intervention). Phase B was the phase in which the intervention or the treatment is given, by considering the change of the dependent variable. The measurement was continued after the treatment (Phase A) (Barlow \& Hersen, 1984).

The measurement used observation of communication behavior during the baseline phase, the intervention, and the follow-up. The measurement included the dependent variable, the verbal and the nonverbal communication which were divided into two stimulus conditions, namely the communication with prompt, and initiation communication (Shriver et al., 2011). The observation was conducted 22 times; 6 times in the baseline phase, 10 times in the intervention phase, and 6 times in the follow-up phase. In a single-case experimental design, the number of baselines contributed to the power of the experiment result, in which the minimum number of the baseline is 2 . The great number of the baseline (for example 5 times of the baseline measurement) and if one of the five measurements is not different, hence the intervention impact will be very clear (Kazdin, 1984).

The dependent variable in this research was the verbal communication and the nonverbal communication observed in two stimulus conditions, e.g. the communication in the presence of prompt (prompt communication), and the communication when there is no prompt (initiative communication) (Shriver et al., 2011).

\section{Table 1.}

Description of Research Variable

\begin{tabular}{|c|c|c|}
\hline Variable & Indicator & Behavior Example \\
\hline \multicolumn{3}{|c|}{ Communication Behavior } \\
\hline Nonverbal (NV) & $\begin{array}{l}\text { Communication used body } \\
\text { language to convey opinion, feeling } \\
\text { and hope without producing sound. }\end{array}$ & $\begin{array}{l}\text { Pointing with finger, raising } \\
\text { shoulders, pulling the cloth to call } \\
\text { someone, shaking head, nodding } \\
\text { head }\end{array}$ \\
\hline Verbal (V) & $\begin{array}{l}\text { Communication was conducted by } \\
\text { using the sound (any volume) to } \\
\text { convey opinion, feeling and hope. }\end{array}$ & $\begin{array}{l}\text { Calling someone's name with voice, } \\
\text { answering questions by producing } \\
\text { voice and asking questions by } \\
\text { producing voice. }\end{array}$ \\
\hline \multicolumn{3}{|c|}{$\begin{array}{l}\text { Stimulus Condition } \\
\end{array}$} \\
\hline $\begin{array}{l}\text { Prompt } \\
\text { Communication }\end{array}$ & $\begin{array}{l}\text { Communication was conducted by } \\
\text { teachers or friends with the student } \\
\text { target (the subject) (or the group in } \\
\text { which the student included one of } \\
\text { the target) by pushing the student } \\
\text { who becomes the target to do the } \\
\text { communication }\end{array}$ & $\begin{array}{l}\text { - Teacher's request that a group of } \\
\text { children sing together in front of } \\
\text { the class. } \\
\text { - Asking questions to the students } \\
\text { who become the target }\end{array}$ \\
\hline $\begin{array}{l}\text { Initiative } \\
\text { Communication }\end{array}$ & $\begin{array}{l}\text { The students communicate verbally } \\
\text { and initiatively both with the }\end{array}$ & $\begin{array}{l}\text { - Asking questions without being } \\
\text { requested }\end{array}$ \\
\hline
\end{tabular}


teacher and friends in the same age - Calling friends spontaneously without the support from the teacher of friends in the same age

The independent variable in this research was the "Kita Semua Sahabat" training. This training uses behavioral techniques, e.g., stimulus fading and contingency management. The technique of stimulus fading in this intervention begins in the situations in which the child is able to communicate well verbally. For instance, if the child feels comfortable at home but has not ever spoken at school, the plan may involve classmates coming to the house to play with the child. Once the child is able to speak comfortably with the classmates, they can go to the park or other playing situations which enable him to play together. It may also be in the schoolyard when other students or teachers are not in the area. The presence of friends is added gradually to increase their confidence. These sessions were conducted before or after school. If the child felt comfortable talking to some friends, another friend could be added to this group. Teachers and other school personnel were added to this group gradually.

The process is gradually camouflaged by adding the number of people when the child feels comfortable talking to the children in that group (this is called the stimulus fading technique). Parents are added to boost the child's confidence and removed gradually when the child feels comfortable in his/her group (Moldan, 2005). The contingency management technique in this research was shown from the reward given (in the form of coin chocolates or snacks) for every verbalization by the subject during the training. The researcher employed the rate of responding a fixed-ratio, in which the subject would get the reward when he/she is eager to communicate verbally 15 times during the intervention period. This technique was chosen since this model is considered the most resulting response which is expected and needs less time (Schunk, 2012). The subject was also given the explanation about the reward scheme, that she would get the reward if she communicated verbally at school 15 times.

The training module in this research was modified from the previous SM researcher (Hartono, 2010). Some modifications made were (1) the research subject was a 5 years-old boy, (2) the subject fell into moderate-severe SM category, (3) the research locations were more varied and involved nature class setting, (4) involving more classmates, (5) different type of games, (6) involving the natural teaching and learning activity and (7) the different measurement was divided into prompt communication and initiative communication.

The data were analyzed using three ways, namely (a) visual, which is a graph of the subject communication development, and (b) quantitative, which is a comparison of means between the baseline phase, the intervention, and the follow up by using one-way ANOVA analysis. 
The subject in the study was a 5 years-old boy, met the SM diagnostic based on DSM V and belonged to the Moderate Severe SM category, who was using nonverbal communication in a certain environment situation but nevertheless using the verbal language fluently at home (Utnick, 2008). The subject refused to speak at school, at public places such as the market, department store, and other unfamiliar places for him. But he wanted to talk at home, to his parents and also to his siblings. He had refused to speak in school since his first year of kindergarten (for 1.5 years), and only used nonverbal language such as pointing or shaking his head when conveying something.

The comprehensive report of the SM diagnosis was the observation result and the interview that was conducted by the researcher. The observation was conducted by two people (interrater observer) to make sure the data's reliability (observer reliability), whereas the interview was conducted by one person (Kazdin, 1984). The diagnosis was conducted by a child psychologist. Written informed consent was obtained from the subject's parents. Parents had already known and approved the procedure and all the risks that might arise in this study. The study was also approved by teachers and the school principal.

\section{Results}

\section{Prompt Verbal Communication and Initiative Verbal Communication}

\section{Figure 2.}

The Development of Verbal Prompt Communication and Verbal Initiation Communication

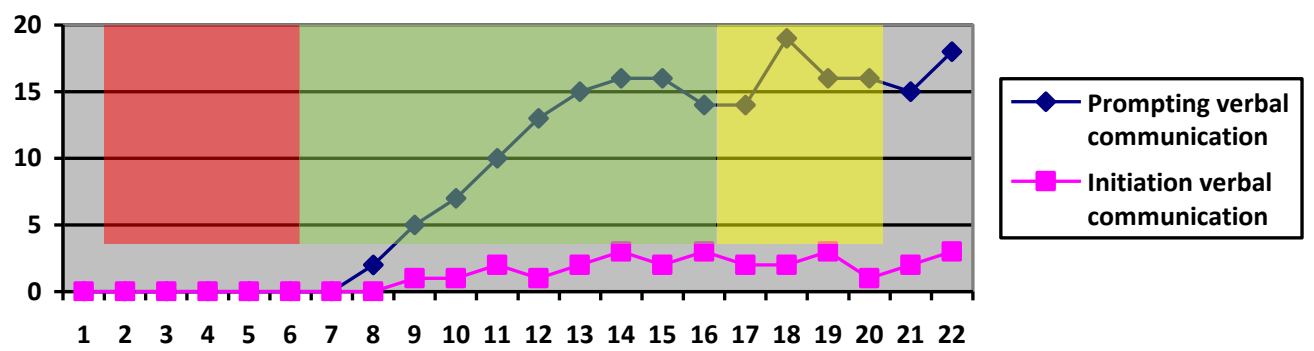

Information :

\begin{tabular}{|l|l|}
\hline & The Baseline Phase \\
\hline & The Intervention Phase \\
\hline The Follow Up Phase \\
\hline
\end{tabular}

The average of the verbal communication with the opportunity or prompt by the subject during the baseline phase I was 0, whereas in the intervention phase was 9.8 and in the follow-up phase was 16.33. The analysis result showed that the value of $F=22.976$, 
$p=0.00(p<0.01)$, meaning that Kita Semua Sahabat Training significantly improved verbal communication with stimulus (prompt communication). The percentage of the training impact could be seen with the formula (Field, 2009):

$$
\begin{aligned}
\Omega^{2}= & J K_{A}-\left(k-1 \cdot M K_{d}\right) \\
& J K_{t}+M K_{d} \\
\Omega^{2}= & 0.67
\end{aligned}
$$

This result shows that the great impact of this training to the subject's verbal communication prompting was $67 \%$. The average value of the initiative verbal communication in the subject during the baseline phase was 0 , whereas in the intervention phase was 1.5 , and the average value of the follow-up phase was 2.1. The Fvalue among the baseline phase, the intervention phase, and the follow up phase were 10.709 with the significance of $0.001(p<0.01)$. This result shows that Kita Semua Sahabat Training was very significant to improve the initiative verbal communication (without prompt). The value of $\Omega^{2}=0.46$. Therefore the significant impact of the training to the improvement of the initiative verbal was $46 \%$.

\section{Prompt Nonverbal Communication and Initiative Nonverbal Communication}

The prompt nonverbal communication at baseline I phase was 1.3, the intervention phase was 2.7, and the follow-up phase was 1.6. The analysis result among the baseline phase, the intervention phase and the follow-up phase showed $F=7.225$ with $p=0.005(p<0.01)$.

\section{Figure 3.}

The Graph of the Prompt Nonverbal Communication and the Initiation Nonverbal

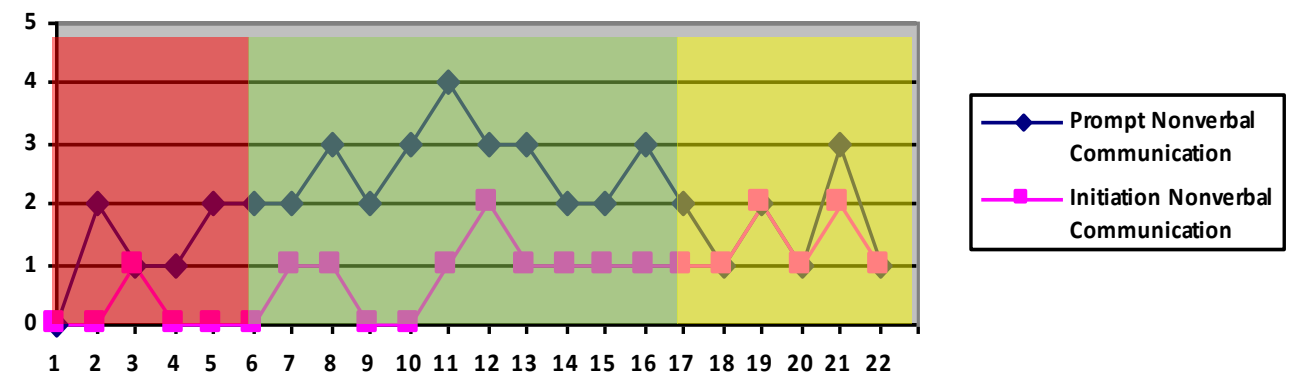

The comparison between the baseline phase and the intervention phase showed $p$ $=0.006(p<0.01$, whereas the comparison between the intervention phase and the followup phase was $0.039(p<0.05)$. Nevertheless, insignificant result happened in the baseline phase to the follow-up phase which showed $p=0.727(p>0.05)$. This result indicates that this training was not significant to improve the prompt nonverbal communication. 
Commonly, the nonverbal communication conducted initiatively during the baseline phase was 0.16 , the intervention phase was 0.9 , whereas the follow-up phase was 1.3. The analysis results among 3 measurements show the value of $F=7.886$ with the value of $p=0.003(p<0.01)$. This result indicates that this training was very significant to improve the initiation nonverbal ability. The value of $\Omega^{2}=0.38$, therefore the big impact of the training to the subject initiative nonverbal communication was $38 \%$.

\section{Table 2.}

Differences in Communication between the Baseline Phase and the Intervention Phase

\begin{tabular}{clccc} 
No & \multicolumn{1}{c}{ Variable } & Sig. of Mean & \multicolumn{2}{c}{ Mean Difference } \\
\cline { 4 - 5 } & & Difference & Baseline & Intervention \\
\hline 1 & Prompt Verbal Communication & $0.001(p<0.01)$ & 0 & 9.8 \\
2. & Initiative Verbal Communication & $0.007(p<0.01)$ & 0 & 1.5 \\
3. & Prompt Nonverbal Communication & $0.006(p<0.05)$ & 1.3 & 2.7 \\
4. & Initiative Nonverbal Communication & $0.033(p<0.05)$ & 0.16 & 0.9 \\
\hline
\end{tabular}

According to Table 2, the training improved prompt verbal communication, initiative verbal and the prompt nonverbal at significant rate with $p<0.01$ during the baseline phase, whereas the initiative nonverbal communication significantly improved with $p<0.05$. The improvement of prompt verbal communication was higher than initiative nonverbal communication (mean difference), but both communication was significantly increased.

\section{Table 3.}

Communication Differences between the Intervention Phase and the Follow Up Phase

\begin{tabular}{clccc}
\hline No & \multicolumn{1}{c}{ Variable } & Sig. of Mean & \multicolumn{2}{c}{ Mean Difference } \\
\cline { 3 - 5 } & & Difference & Intervention & Follow Up \\
\hline 1 & Prompt Verbal Communication & $0.019(p<0.05)$ & 9.8 & 16.3 \\
2. & Initiative Verbal Communication & $0.295(p>0.05)$ & 1.5 & 2.1 \\
3. & Prompt Nonverbal Communication & $0.039(p<0.05)$ & 1.7 & 1.6 \\
4. & Initiation Nonverbal Communication & $0.260(p>0.00)$ & 0.9 & 1.3 \\
\hline
\end{tabular}

According to Table 3, prompt verbal communication improved significantly, nevertheless the prompt nonverbal communication decreased significantly. The initiative verbal communication and the initiative nonverbal communication did not increase significantly. The prompt verbal communication was significantly increased $(p<0.05)$ while initiative verbal communication is not significantly increased $(p>0.05)$ if we compare the intervention and follow-up phases. 
WIJAYANTI \& MURTINI I| IMPROVING COMMUNICATION ABILITY

Table 4.

Communication Differences between the Baseline Phase and the Follow Up Phase

\begin{tabular}{clccc}
\hline No & \multicolumn{1}{c}{ Variable } & Sig. of Mean & \multicolumn{2}{c}{ Mean Difference } \\
\cline { 3 - 5 } & & Difference & Baseline & Follow Up \\
\hline 1 & Prompt Verbal Communication & $0.001(p<0.01)$ & 0 & 16.3 \\
2. & Initiative Verbal Communication & $0.001(p<0.01)$ & 0 & 2.1 \\
3. & Prompt Nonverbal Communication & $0.727(p>0.05)$ & 1.3 & 1.6 \\
4. & Initiation Nonverbal Communication & $0.003(p<0.01)$ & 0.16 & 1.3 \\
\hline
\end{tabular}

According to Table 4, by comparing the condition before and after the training (the baseline and the follow-up), this training was significant to improve prompt verbal communication, the initiative verbal communication, and initiative nonverbal communication. The prompt nonverbal communication did not improve significantly if it is compared to the baseline phase. After the intervention, the subject's verbal communication tended to improve, but the nonverbal communication tended to decrease after the implementation of the intervention.

\section{Discussion}

According to the findings, the child's communication improved after the training, especially verbal communication both in prompt verbal communication and also initiative verbal communication. The intervention in this research was conducted on a 5 years old boy using a behavioral-based approach (stimulus fading and contingency management), several researchers reported that behavioral intervention is suitable for younger children with SM. Meanwhile, a form of active cognitive restructuring as a component of cognitive-behavioral therapy (CBT) could be particularly important for older children (Oerbeck et al., 2020). Support for the latter is the beneficial effect also found in older children after a modular treatment of SM including a cognitive component (Lang et al., 2016). Intervention in early childhood has been found to be related to the decreased probability of the development of psychopathology later on. The plasticity and resiliency associated with early childhood may provide the individual with the resources to adapt and incorporate skills from treatment more readily; or, young children may be less conditioned toward their particular "disorder" behavior and thus the influence of purposeful, efficient treatment could have a stronger and more lasting impression at this early developmental stage (Conn \& Coyne, 2014).

Individuals with SM demonstrate a consistent failure to speak in specific social situations (at school) despite speaking in others (at home). This disorder may result in social impairments as children become too anxious to socially interact. Intervention with SM children should be conducted to reduce the anxiety and improve their self-confidence in their social situation (Klein et al., 2017). Along with decreasing their anxiety and increasing their self-confidence, so communication will appear. In the Kita Semua 
Sahabat Training, the subject level anxiety was decreased slowly through the combination of stimulus fading and contingency management techniques. The stimulus fading technique in this research is started in the situation which is comfortable for the children, that is at home and later being introduced to the environment which is more complex outside the house gradually, such as friends' houses, recreation places, and schools. The number of people was also added gradually when the subject felt comfortable. The implementation of contingency management was giving rewards as the reinforcement for verbal communication shown by the subject during the intervention phase. The result showed that there is an improvement in the verbal communication frequency from the baseline to the intervention. The training result also remained at the follow-up.

The combination of the stimulus fading and contingency management technique in this research is the development of the base principle of the $A B C$ behavior theory (Vecchio, 2009). The stimulus is presented to the subject (which is the antecedent condition, that is when other people invite the subject to speak). The subject then responds to the stimulus by giving the answer verbally (behavioral). Then, other people will give the reward to verbal communication she does (contingency management technique as the consequences). The scheme is repeated continuously to become the subject's new habit and affect her to be more eager to speak. And this form succeeds in improving the subject of verbal communication. The result is also in line with some previous studies of the effectiveness of behavioral strategies about stimulus fading and contingency management to treat children with SM (Beare et al., 2008; Hartono, 2010; Vecchio, 2009). Among all the interventions used to treat SM, behavioral interventions were the most effective and had the strongest research report, because it focuses on behavioral change of the subject (Busse \& Downey, 2011).

The increased frequency of verbal prompt communication was more than verbal initiative communication (Picture 1). Statistical analysis showed that the improvement of prompt verbal communication at $67 \%$, whereas the initiation verbal communication shows $47 \%$. This is because for the SM child, initiatively inviting others to communicate is the most prevented thing for him/her, and to turn up the communication of the SM child cannot be forced (Shipon Blum, 2003). A similar thing also happens to the subject, wherein the condition that there are fewer stimuli, she seldom tentatively speaks to others. The communication he did was still limited to answering questions from his friends or teachers. Starting a conversation is difficult for the SM child, and it needs a long process (Shriver et al., 2011). The importance of the stimulus for the SM child is to help them to increase the communication response. For an SM child, it is easier to answer the questions and give the response than having to ask a question or give a comment (Krysanski, 2003).

We found an interesting finding that the improvement of prompt nonverbal communication was not significant, even tended to decrease after the intervention. The prompt nonverbal communication development was in contrast with the verbal 
communication, the verbal communication was improved, and the nonverbal communication tended to decrease, which is shown in Figure 4.

\section{Figure 4.}

Comparison Between Prompting Verbal and Nonverbal Communication

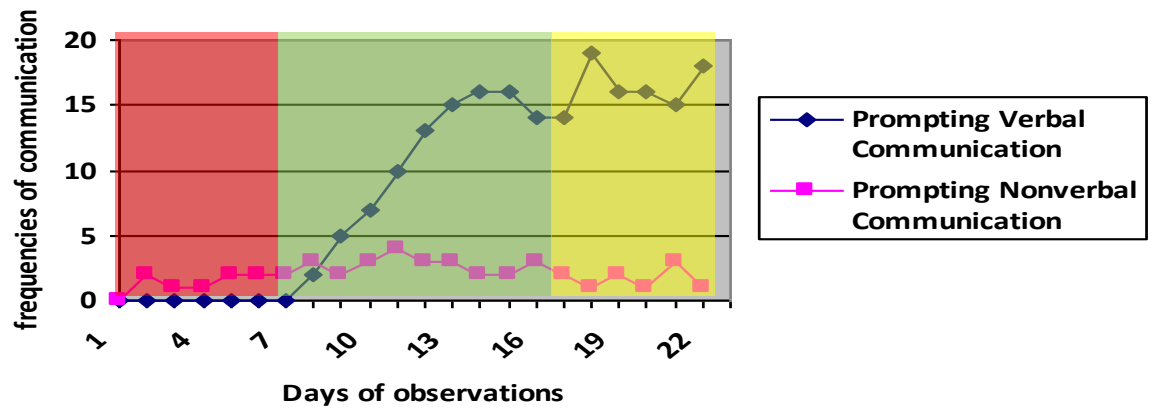

This research is in line with the intervention technique of this research. The intervention technique used is the giving of the reward when she speaks (doing the verbal communication), with this technique; students learn that she will get the reward if she speaks. Therefore, the subject will try to respond to the environment with verbal communication as often as possible, and it makes the nonverbal communication tend to decrease. In line with the (Shriver et al., 2011) research who finds that there is an improvement of the prompt verbal communication which is significant after the intervention using the stimulus fading and the contingency management technique.

In the intervention phase and the follow-up phase, the subject experiences a significant advancement even though the training has ended. The intervention to the SM child is conducted step by step along with the comfort they feel. Along with the comfort feeling they had by using verbal communication, nonverbal communication will be decreased (Bergman, 2013). This training could be considered as one of the effective training of SM children even when the treatment is over. Several studies have also found the efficacy of behavioral approach intervention to increase functional speech and decrease SM symptoms, and follow-up results showed increased functional speech, maintained at 3 months (Bergman, 2013). The behavioral intervention focused on stimulus fading and contingency management was very useful to decrease their anxiety and increase their self-confidence. As their self-confidence increases, the child will be more courageous to interact with his environment. Of course, social support becomes crucial to maintaining this desired behavior after the treatment. Younger children receiving treatment showed higher speaking frequency and lasting results (Oerbeck et al., 2014).

The research design was a single case experimental design. It means that the study employed a single subject as the participant. Therefore, the research result is challenging to be generalized. Meanwhile, several researchers had stated that the single case experimental design is an experimental design that can help identify the effectiveness of 
specific treatment and in describing individual-level effects (Byiers et al., 2014). Individual uniqueness becomes an important consideration in the treatment process, therefore the single case experimental design is more suitable for examining whether an intervention is effective or not for a "disorder". The study focused more on the effectiveness of behavioral approach intervention for SM children, with moderate-severe category. Further research could implement the intervention procedure with the same category of an SM child, or even a different category, just to find out whether the intervention is still effective or not. This research, though, had the weakness that the subject was only one person, one gender, and had no control group makes this research difficult to be generalized. Further study is suggested to use some subjects with different genders to corroborate the effectiveness of this training (Lang et al., 2016).

\section{Conclusion}

The training of "Kita Semua Sahabat" significantly improves communication of children with SM. The increase of prompt verbal communication was greater than initiative verbal communication. Our interesting finding is that the prompt nonverbal communication tends to decrease; meanwhile the prompt verbal communication has increased significantly. As the child's anxiety decreased, their speech increased. Follow-up study showed that the result remained, because the subject's self-confidence increased as long as he received support from their environments.

\section{Suggestion}

Because the study used a single case experimental design, further study is suggested to replicate the intervention to different categories of SM Child, different gender and adding a control group to discover whether the intervention is also effective or not.

\section{Acknowledgement}

The author would like to thank Prof. Amitya for the inspiring discussion that lead to the research, and also Prof. Saifuddin Azwar for his helpful inputs and support.

\section{Authors' contribution}

PAKW and $\mathrm{M}$ conceived of the presented idea. PAKW developed the theory, carried out the experiment, and performed the analytical statistics. $M$ encouraged first author to investigate a specific aspect and supervised the findings of this work. All authors discussed the result and contributed to the final manuscript.

\section{Conflict of interest}

The authors declared no potential conflict of interest with respect to the research, authorship, and/or publication of this article. 
WIJAYANTI \& MURTINI II IMPROVING COMMUNICATION ABILITY

\section{Funding}

The authors received no financial support for the research, authorship, and/or publication of this article.

Orcid ID

Puspita Adhi Kusuma Wijayanti 0000-0002-5177-4239

\section{References}

American Psychiatric Association (APA). (2013). Diagnostic and manual of mental disorder (5th ed.). American Psychiatric Association.

Barlow, D. H; \& Hersen, M. (1984). Single case experimental design: Strategies for studying behavior change (2nd ed.). Pergamon Press.

Beare, P., Torgerson, C., \& Creviston, C. (2008). Increasing verbal behavior of a student who is selectively mute. Journal of Emotional and Behavioral Disorders, 16(4), 248-255. https://doi.org/10.1177/1063426608317356

Bergman, L. (2013). Treatment for children with selective mutism: An integrative behavioral approach. Oxford University Press.

Busse, R. T., \& Downey, J. (2011). Selective mutism: A three-tiered approach to prevention and intervention. Contemporary School Psychology, 15, 53-63. Retrieved from http://www.casponline.org/pdfs/pdfs/2011_journal_all_001-144.pdf\#page=55

Byiers, Breanne., Reichle, Joe., Symons, F. J. (2014). Single subject experimental design for evidence-based practice. Am J Speech Lang Pathol, 23(4), 397-414. https://doi.org/10.1044/1058-0360(2012/11-0036).Single-Subject

Carbone, D., Schmidt, L. A., Edison, S., Pierre, J. S., \& Boyle, M. H. (2010). Behavioral and socio-emotional functioning in children with selective mutism: A comparison with anxious and typically developing children across multiple informants. Journal of Abnormal Child Psychology, 38, 1057-1067. https://doi.org/10.1007/s10802-010-9425-y

Conn, B. M., \& Coyne, L. W. (2014). Selective mutism in early childhood: Assessment and treatment of an African American preschool boy. Clinical Case Studies, 13(6), 487500. https://doi.org/10.1177/1534650114522912

Diliberto, R. A., \& Kearney, C. A. (2016). Anxiety and oppositional behavior profiles among youth with selective mutism. Journal of Communication Disorders, 59, 16-23. https://doi.org/10.1016/j.jcomdis.2015.11.001

Fernandez, K. T. G., \& Sugay, C. O. (2016). Psychodynamic play therapy: A case of selective mutism. International Journal of Play Therapy, 25(4), 203-209. https://doi.org/10.1037/pla0000034

Hartono, M. A. (2010). Pelatihan sahabat anak untuk meningkatkan komunikasi pada anak selective mutism. Universitas Gadjah Mada.

Kazdin, A. E. (1984). Behavior modification in applied settings. Dorsey Press.

Klein, E. R., Armstrong, S. L., Skira, K., \& Gordon, J. (2017). Social Communication 
Anxiety Treatment (S-CAT) for children and families with selective mutism: A pilot study. Clinical Child Psychology and Psychiatry, 22(1), 90-108. https://doi.org/10.1177/1359104516633497

Krysanski, V. L. (2003). A brief review of selective mutism literature. Journal of Psychology: Interdisciplinary and Applied, 29-40. https://doi.org/10.1080/00223980309600597

Lang, C., Nir, Z., Gothelf, A., Domachevsky, S., Ginton, L., Kushnir, J., \& Gothelf, D. (2016). The outcome of children with selective mutism following cognitive behavioral intervention: a follow-up study. European Journal of Pediatrics, 175(4), 481-487. https://doi.org/10.1007/s00431-015-2651-0

Longobardi, C., Badenes-Ribera, L., Gastaldi, F. G. M., \& Prino, L. E. (2019). The studentteacher relationship quality in children with selective mutism. Psychology in the Schools, 56(1), 32-41. https://doi.org/10.1002/pits.22175

Manassis, K., Tannock, R., Garland, E. J., Minde, K., McInnes, A., \& Clark, S. (2007). The sounds of silence: Language, cognition, and anxiety in selective mutism. Journal of the American Academy of Child and Adolescent Psychiatry, 46(9), 1187-1195. https://doi.org/10.1097/CHI.0b013e318076b7ab

Moldan, M. B. (2005). Selective mutism and self-regulation. Clinical social work journal, 33(3), 291-307. https://doi.org/10.1007/s10615-005-4945-6

Muris, P., \& Ollendick, T. H. (2015). Children who are anxious in silence: A review on selective mutism, the new anxiety disorder in DSM-5. Clinical Child and Family Psychology Review, 18(2), 151-169. https://doi.org/10.1007/s10567-015-0181-y

Nowakowski, M.E., Cunningham, C., McHolm, A., Evans, M., Edison, S., Pierre, J., Boyle, M., Schmidt, L. (2009). Language and academic abilities in children with selective mutism. Infant and Child Development, 18(6), 271-290. https://doi.org/10.1002/icd

Oerbeck, B., Overgaard, K. R., Bergman, R. L., Pripp, A. H., \& Kristensen, H. (2020). The selective mutism questionnaire: Data from typically developing children and children with selective mutism. Clinical Child Psychology and Psychiatry, 25(4), 754765. https://doi.org/10.1177/1359104520914695

Oerbeck, B., Stein, M. B., Wentzel-Larsen, T., Langsrud, Ø., \& Kristensen, H. (2014). A randomized controlled trial of a home and school-based intervention for selective mutism - defocused communication and behavioural techniques. Child and Adolescent Mental Health, 19(3), 192-198. https://doi.org/10.1111/camh.12045

Petry, N. M. (2011). Contingency management: What it is and why psychiatrists should want to use it. Psychiatrist, 35(5), 161-163. https://doi.org/10.1192/pb.bp.110.031831

Ponzurick, J. M. (2012). Selective mutism: A team approach to assessment and treatment in the school setting. Journal of School Nursing, 28(1), 31-37. https://doi.org/10.1177/1059840511422534

Santrcok, J. W. (2018). Life Span Development (17th ed.). McGraw-Hill Education.

Schunk, D. H. (2012). Learning theories: An educational perspective (6th ed.). Pearson 
Education.

Shabani, D. B., \& Fisher, W. W. (2006). Stimulus fading and differential reinforcement for the treatment of needle phobia in a youth with autism. Journal of Applied Behavior Analysis, 39(4), 449-452. https://doi.org/10.1901/jaba.2006.30-05

Shaffer, D. R. (2009). Social and personality development. Wadsworth Cengage Learning.

Shipon Blum, E. (2003). The ideal classroom setting for the selectively mute child. Selective Mutism Anxiety Research and Treatment Center.

Shriver, M. D., Segool, N., \& Gortmaker, V. (2011). Behavior observations for linking assessment to treatment for selective mutism. Education and Treatment of Children, 34(3), 389-411. https://doi.org/10.1353/etc.2011.0023

Utnick, G. E. (2008). Behavioral interventions with selectively mute students: strategies $\mathcal{E}$ symptom severity. Paper Presentation at NASP. http://schooled.brooklyn.cuny.edu/Utnick\%20Selective\%20MutiSM\%2S lides.pdf

Vecchio, J. L. (2009). The treatment of selective mutism: A case control alternating treatments design. Dissertation Abstracts International: Section B: The Sciences and Engineering, 7154. Retrieved from https://www.lib.uwo.ca/cgibin/ezpauthn.cgi?url=http://search.proquest.com/docview/622057366?accountid=1 5115\%5Cnhttp://vr2pk9sx9w.search.serialssolutions.com/?ctx_ver=Z39.882004\&ctx_enc=info:ofi/enc:UTF8\&rfr_id=info:sid/PsycINFO\&rft_val_fmt=info:ofi/fmt 